\title{
Breast Cancer in Europe: Epidemiology, Risk Factors, Policies and Strategies. A Literature Review
}

\author{
Bashaier Abdullah Aljohar ${ }^{1} \&$ Mohammed Ahmedhani Kilani ${ }^{1}$ \\ ${ }^{1}$ Faculty of Health, Medicine and Life Sciences, Maastricht University, Maastricht, The Netherlands \\ Correspondence: Bashaier Abdullah Aljohar, Faculty of Health, Medicine and Life Sciences, Maastricht University, \\ Universiteitssingel 40, 6229 ER Maastricht, Netherlands. E-mail: b.aljohar@student.maastrichtuniversity.nl
}

Received: March 18, 2018 Accepted: August 24, 2018 Online Published: October 13, 2018

doi:10.5539/gjhs.v10n11p1 URL: https://doi.org/10.5539/gjhs.v10n11p1

\begin{abstract}
Introduction: Breast cancer is the most commonly diagnosed cancer in European women, accounting for 28.8\% of the total number of cancer diagnosis in Europe. Over the past few decades, several factors have led to remarkable improvements in overall breast cancer outcomes in Europe, such as early detection, screening, and progresses in treatment. However, breast cancer remains the most common cancer in females in Europe, yet more there is an increase in the incidence and mortality rates in some European countries. This research summarizes the current status of breast cancer in Europe, including epidemiology, risk factors, policies, and strategies. The results can help to better identify this health problem, which could help in developing better breast cancer control or prevention strategies and policies.
\end{abstract}

Methods: A literature review was conducted using five electronic databases (PubMed, Google Scholar, ProQuest, Eurostat, BioMed) and the European Commission reports for studies that reported on epidemiology and risk factors of breast cancer, or policies and strategies that target it in Europe. In addition, the Social Ecological Model (SEM) was used in categorizing the breast cancer risk factors into different levels.

Results: Europe and North America have the highest rate of breast cancer globally. Incidence and prevalence of breast cancer vary across Europe, and so does its mortality rates. Breast cancer was found to be associated with a number of risk factors, including but not limited to aging, use of hormone therapy, older age at the first birth, and smoking which are common in Europe. Cancer in general, and breast cancer have attracted specific attention, and the European Union has focused many of the resources and expertise on the topic.

Conclusion and Recommendations: Breast cancer remains a major public health issue in Europe, despite the efforts and actions being taken. Therefore, current efforts against breast cancer in Europe need to be revisited and improved.

Keywords: breast cancer, epidemiology, risk factors, health policies, Europe

\section{Introduction}

\subsection{Background}

During the twentieth century, non-communicable diseases (NCDs) also known as "diseases of modern life" became the main causes of morbidity and mortality in industrialized countries, as well as in many low-income countries (Tulchinsky \& Varavikova, 2010). In 2015, NCDs caused 70 percent of all global deaths (World Health Organization [WHO], 2014). Europe is the most affected region by NCDs, and the number is still increasing. Cardiovascular diseases, cancer, respiratory diseases and diabetes are the major NCDs in the European region. These together are responsible for nearly $77 \%$ of the burden of disease and approximately $86 \%$ of deaths in the region (WHO, 2013).

Cancer refers to a group of diseases that result in changes and out of control growth of cells. Eventually, the majority of cancer types form a mass or an aggregation of cancer cells known as a tumor. These tumors are named according to the part of the body involved. When it comes to breast cancer, the majority of these tumors arise from the glandular tissue of the breast, or what is known as lobules, and also from the ducts that connect these lobules to the nipple. The detection of breast cancer is usually done through a screening examination, even before symptoms develop, or when the patient feels a lump in the breast. Typically, most of the breast masses can be seen on a mammogram, and the majority of breast lumps are found to be benign, which means that they are not cancerous, 
they do not grow out of control, or metastasize to other parts of the body, in other words, they are not life-threatening. To determine whether a lump is cancerous or not, a tissue biopsy is needed for microscopic analysis to reach a definitive diagnosis about the lump, the extent of spread, characters, and type of the lump. There are two ways to obtain the tissue biopsy for microscopic analysis, either by using fine needle aspiration or by surgical biopsy, and the decision to use either depends on the individual clinical factors and the availability of biopsy devices and resources (American Cancer Society, 2015).

In 2015 , breast cancer was the leading cause of cancer mortality and morbidity among women worldwide, with an estimated 2.4 million cases and around 523000 deaths (Fitzmaurice et al., 2017). Moreover, it is the most commonly diagnosed cancer in women worldwide. Furthermore, every year, one in ten of all new cancers diagnosed around the world is female breast cancer (Jacques Ferlay, Héry, Autier, \& Sankaranarayanan, 2010). Approximately, 55 percent of the worldwide burden of breast cancer is experienced in industrialized countries. However, the incidence of breast cancer is rapidly increasing in low-income countries (Jacques Ferlay et al., 2010).

There are wide geographical variations in breast cancer incidence rates (Porter, 2009). Europe and North America have the highest rate of breast cancer worldwide. There, an estimate of 1 in 9 women is at risk of developing it. In contrast, Asia and Africa have the lowest rates (Torre et al., 2015). Globally, the incidence rate of breast cancer varies greatly across the different regions, ranging from 27 per 100,000 in Middle Africa and Eastern Asia to 96 per 100,000 in Western Europe. This variation is possibly the result of a combination of differences in the availability of screening programs (thus under detection in some countries), the prevalence of risk factors, and the accessibility to effective treatment (Altobelli \& Lattanzi, 2014). Nevertheless, the differences in mortality rates across regions are smaller, as a result of the more favorable survival after breast cancer in the developed regions, despite the higher incidence (International Agency for Research on Cancer [IARC], 2016).

Over the last few decades, many epidemiological studies have shown risk factors associated with breast cancer. Such risk factors include genetic, hormonal, reproductive, diet and lifestyle factors. Breastfeeding and giving birth to a child decrease the risk of breast cancer. Moreover, early detection of breast cancer significantly improves survival and increases treatment options (Torre et al., 2015). Breast cancer risk factors in Europe require more investigation. Knowing them is vital to determine how to address this health problem. Therefore, researching the problem again, and looking at the behaviors and factors that triggered it, would allow better interventions. Consequently, it is important to identify and address the factors at different levels that put European populations at risk for, or protect them against, breast cancer. This is expected to help in the improvement or development of effective breast cancer prevention strategies and policies by the European Union (EU).

\subsection{Aim and Objectives}

The overall aim of this research is to investigate breast cancer epidemiology, risk factors, and related European policies and strategies.

The research objectives are the following:

1) Map the epidemiology of breast cancer in the European region.

2) Identify breast cancer risk factors relevant to European populations.

3) Investigate existing EU policies and strategies concerning breast cancer

\subsection{Theoretical Framework}

The social ecological model (SEM) (figure1) focuses on multiple factors that could affect the human health. The ecological model organizes risk factors and protective strategies into four levels of a nested hierarchy. These levels are: the individual, relationship, community, and society. This comprehensive model claims that no single factor can explain the etiology of a certain health problem and investigates why this health problem is more prevalent in some communities than others. However, the model considers that health can be affected by the interaction between different factors from the four different levels. Understanding how these factors are related to each other and to the health problem is one of the essential steps in the public health prevention approaches (Krugg, Dahlberg, Mercy, Zwi, \& Lozano, 2002).

The model highlights the complex role played by context in the development of health problems and identifies the successfulness of attempts addressing these problems. Community leaders, researchers, and public health professionals can use this model to determine factors at different levels (individual, relationship, community, and society) that lead to a certain health problem and to develop suitable prevention and health promotion approaches that include actions at these four levels. This comprehensive approach focuses on combining approaches to change the surrounding environments rather than only adjusting individual health practices (McCloskey, McDonald, \& 
Cook, 2013).

The first level of the model, individual, identifies biological and personal characteristics, such as health history, age, income, and education. The second level, relationship, looks at an individual's close social circle that may influence a person's behavior and practices such as partners, family members, and friends. The third level, community, examines the settings in which social networks occur, such as neighborhoods, schools, and workplaces to determine the factors of these settings that could affect health. Finally, the fourth level of the ecological framework, societal, includes the broader social factors that have an important role in the support or impairment of human health, such as cultural norms, economic, health education and social policies that produce, maintain, or reduce social and economic inequalities between social groups (Krugg et al., 2002).

This framework is relevant for the topic discussed in this research. Indeed, breast cancer is a complex disease with, except some rare cases, no single cause. Many factors at different levels can contribute to breast cancer. Firstly, individual level factors include age, gender, income, genetic factors and personal and family history of breast cancer. Secondly, relationship level factors include, for example, having children or not. Thirdly, community-level factors may include occupational conditions and access to health services. Finally, public awareness and education are amongst the societal level factors relevant for breast cancer. Furthermore, this model allows us to assess the programs and policies that address breast cancer.

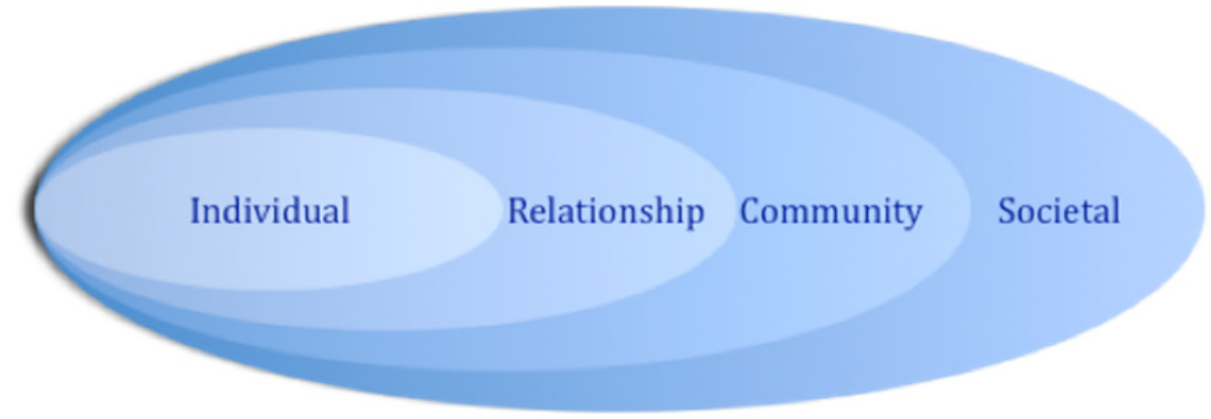

Figure 1. The Social Ecological Model: A Framework for Prevention (Dahlberg \& Krugg, 2002)

\section{Methodology}

A narrative literature review was conducted in order to address the three research objectives. These objectives were breast cancer epidemiology in Europe, breast cancer risk factors relevant to European populations and breast cancer strategies, and policies in Europe.

Regarding breast cancer epidemiology in Europe data were obtained from the International Agency for Research on Cancer (IARC), several journal articles, and the European Commission reports. Most of the data used were from 2012 as it was the most recent aggregated estimations. The epidemiological data were collected through looking at global European trends, as well as different European regions and countries to obtain an overall view of the European perspective in breast cancer.

Concerning breast cancer risk factors relevant to European populations, several databases were searched, such as PubMed, Google Scholar, ProQuest, Eurostat, BioMed. In addition, several publications from The European Prospective Investigation into Cancer and Nutrition (EPIC) were used, particularly in the lifestyle factors.

Inclusion and exclusion criteria in this research were: English language and publications from 2000. Papers that are not relevant to the EU level or its perspective were excluded.

Regarding breast cancer strategies, and policies in Europe, websites, and reports from European institutions were used such as the World Health Organization Regional Office for Europe (WHO/Europe), the European Commission, the European Parliament and The European Breast Cancer Coalition (EUROPA DONNA).

The possible keywords in the online search included a combination of the following terms: breast cancer, Epidemiology, incidence, mortality, trend, risk factors, prevention, Europe, European Union, policies, strategies, and initiatives 


\section{Results}

\subsection{Epidemiology of Breast Cancer in Europe}

Breast cancer is the most common type of cancer diagnosed in European women, accounting for 28.8 percent of the total number of cancer diagnosis (J Ferlay et al., 2013). The incidence of breast cancer in Europe is more than two times the new breast cancer cases in any other region (EUROPA DONNA, 2015). It results in a considerable health burden on populations, as well as on healthcare systems. The health care expenditure on breast cancer management and treatment in the EU in 2009 was $€ 15$ billion, which represents 12 percent of the overall economic cost of cancer in the EU (Luengo-Fernandez, Leal, Gray, \& Sullivan, 2013). Furthermore, it is the second most common cause of cancer mortality (after lung cancer) in females in developed countries (Jacques Ferlay et al., 2015). Between the 80s and the late 90s, breast cancer incidence rates increased approximately 30 percent in Western nations. This increase was likely due to the use of menopausal hormone therapy, and changes in reproductive factors. In the early $2000 \mathrm{~s}$, there was a decrease in incidence rate because of reduced use of menopausal hormone therapy in nations where it was previously common, such as the United Kingdom and France (Torre et al., 2015). In addition to changes in menopausal hormone therapy usage, decreasing incidence rates in Western nations might also attributable to a plateau in mammographic screening participation rates (Youlden et al., 2012).

From the 50 s to the late 80 s, breast cancer mortality rates increased in the whole Europe, except in Sweden and Norway. Breast cancer deaths reached a peak in the 1990s, at 14.74 deaths per 100,000 people in 1994, declining to 13.01 per 100,000 in 2009 (European Commission, 2016). This reduction has been attributed to early detection via mammography and improved effective treatment (Torre et al., 2015). Holleczek, Arndt, Stegmaier, and Brenner (2011) state that during the past three decades, due to the progress and advancement in the medical procedures involved in the treatment of breast cancer in the Western world, the age-standardized 5-year relative survival rates in Europe has increased from 73\% to 83\% in the period between 1992 and 2008.

A retrospective study of breast cancer mortality trends among women across 30 European nations based on World Health Organization data from 1989 to 2006 showed significant changes in breast cancer mortality trends across countries. Ranging from 45 percent decrease in Iceland to a 17 percent increase in Romania. Almost all Northwestern European nations experienced decreases, such as England, Scotland, Sweden, and France, whereas increases were reported in Central European countries, such as Estonia, Greece, and Latvia, (Autier et al., 2010).

According to the estimates of the IARC in the year 2012, breast cancer was responsible for 361608 cases in the 28 EU member states with 91585 deaths (IARC, 2016). Overall, the use of mammography screening and the promotion of clinical breast examination strategies have raised the survival rate across all breast cancer stages to exceed 90 percent in the European region. Thus, in spite of the yearly mortality rates due to breast cancer, the pool of breast cancer survivors is seen to continue growing rapidly (Brown, Winters - Stone, Lee, \& Schmitz, 2012).

In 2012, the incidence varied by nearly 100 percent across European regions. The highest rates were found in Western and Northern European countries, where an estimate of 96.0 and 89.4 cases per 100,000 people were reported, respectively. Followed by Southern Europe, where an estimate of 74.5 cases per 100,000 was reported. The lowest incidence rate was reported in Central and Eastern Europe, with an estimate of 47.7 cases per 100,000 (Torre et al., 2015). In the same year, among European Union countries, there was a great difference (49-148 per $100,000)$ of incidence rates, which showed a clear geographical pattern. Countries in West and North Europe were found to have high incidence, such as in Belgium $(147$ per 100,000), France $(137$ per 100,000) and The Netherlands (131 per 100,000), the United Kingdom (129 per 100,000), as well as the Nordic countries, Denmark (143 per 100,000), Iceland (131 per 100,000) and Finland (121 per 100,000). On the other hand, East European countries had lower incidence rates as indicated in the introduction. That was the case for Ukraine (54 per 100,000) and Moldova (53 per 100,000). Additionally, there were variations in the mortality rates as well, but to a lesser extent. The highest mortality rates were in the southern parts of Europe (Serbia 31, and Macedonia 36 per 100,000), as well as in some of the west and north European countries like Belgium (29 per 100,000) and Denmark (28 per 100,000). Mortality rates were lowest in Estonia (15 per 100,000) in northern Europe, as well as in Spain and Bosnia Herzegovina (17 per 100,000) in southern Europe. These numbers have different interpretations, as the high mortality figures in the north and western European countries reflect the high incidence rates. In contrast, the higher high mortality rates in the southern European countries reflect a worse prognosis than the north, as the ratio of mortality to incidence rate is higher (J Ferlay et al., 2013).

\subsection{Risk Factors of Breast Cancer in Europe}

Despite the progression in science and medicine, the exact causes of breast cancer are still unknown. Breast cancer 
is a complex disease with no single cause or risk factor. A combination of internal and external factors influences an individual's risk of developing it. Many scientific studies have found a number of factors that increase the risk of developing breast cancer. Some of them are non-modifiable factors, such as gender, age, family history, early menarche, and late menopause. Modifiable factors include obesity, use of combined estrogen and progesterone pills, alcohol intake, and breastfeeding. The factors are classified into the following five categories: "gender, age, and race", "personal history, family history, and genetic susceptibility", "reproductive factors", "hormonal factors", "lifestyle factors", and "environmental factors".

\subsubsection{Demographic Characteristics}

\subsubsection{Gender, Age, and Race}

Among the most significant risk factors are female gender and advancing age. Ninety-nine percent of breast cancer cases are women. Moreover, breast cancer incidence and mortality rates generally rise with age. The incidence of breast cancer is directly associated with age, indeed the chances of developing breast cancer in women under 25 years old are very low. The probability increases gradually until the age of 60 years, after which the incidence rates increase dramatically (Lewis, Dirksen, Heitkemper, \& Bucher, 2013). In Europe, an average of 20 percent of breast cancer cases occur in women younger than 50 years of age, approximately half of breast cancer cases (48 percent) occur at age 50-69 and the rest of the cases are found in women above this age (Table1) (Ferlay et al., 2013). It is estimated that in EU-28, 1 in 8 women will have developed breast cancer before the age of 85.3 (EUROPA DONNA, 2015).

Table 1. Breast cancer cases in 2012 in European women by age

\begin{tabular}{lll}
\hline Age groups & Number of cases & Percentage (\%) \\
\hline$<50$ & 93411 & $20.4 \%$ \\
$50-59$ & 106212 & $23 \%$ \\
$60-69$ & 114894 & $25 \%$ \\
$70+$ & 144201 & $31.44 \%$ \\
Total & 458718 & \\
\hline
\end{tabular}

Adapted from “Cancer Incidence and Mortality Worldwide: IARC CancerBase No. 11”, by Ferlay, J et al., (2013). Retrieved from: http://globocan.iarc.fr

Jing, Su, and Ring (2014) stated in their systematic review that there is a distinction in incidence, prevalence, and mortality of many cancers associated with ethnicity. Such distinctions have also been reported in breast cancer. For example, in the United States, the incidence of breast cancer is markedly lower in Hispanic and Native American women. These distinctions are hypothesized to be due to different causes, including intrinsic differences, for example, genetic variation, and extrinsic differences, represented in differences in social, economic, and geographical environments. Likewise, Fejerman et al. (2010) reported an increased risk of breast cancer in Mexican women with greater European ancestry compared to women with lower European ancestry. The difference reported is stark, as women with $76 \%$ to $100 \%$ European ancestry were found to have double the risk compared to those with $0 \%$ to $25 \%$ European ancestry. The author reported that a $25 \%$ increase in European ancestry corresponds to $20 \%$ increase in the likelihood of breast cancer.

\subsubsection{Socioeconomic Status}

A systematic review and meta-analysis were recently conducted looking at the association between socioeconomic status (SES) and breast cancer incidence and mortality in Europe. The study showed that women with higher socioeconomic status are significantly at higher risk of developing breast cancer. This increased risk could be explained by the fact that women from higher socioeconomic classes can afford regular mammography screening, as well as hormone replacement therapy, and have different reproductive factors such as breastfeeding, and lifestyle. Moreover, females with higher SES have significantly lower-case fatality, which can be partly due to variations in the characteristics of the tumor, treatment factors, comorbidities and lifestyle factors. In addition, women with lower SES tend to have lower screening attendance when compared to women from higher SES, influencing breast cancer risk and outcome (Lundqvist, Andersson, Ahlberg, Nilbert, \& Gerdtham, 2016). 


\subsubsection{Personal History, Family History, and Genetic Susceptibility}

The human body has genes that protect or promote the development of cancers. Well-known genes that are linked to breast cancer risk are tumor suppressors BRCA1 and BRCA2. The products of these two genes play an important role protecting against ovarian and breast cancer by repairing damaged DNA, which could cause uncontrolled cell growth. When harmful mutations occurs in either BRCA1 or BRCA2 genes, damaged the DNA repair process is less efficient or deficient. Women with inherited mutations in the tumor suppressor genes BRCA1 and BRCA2 have a significantly higher risk of developing breast cancer. Mutations in these two genes together are responsible for approximately 20 to 25 percent of hereditary breast cancers and less that 5 percent of all familial breast cancers incidence (Oldenburg, Meijers-Heijboer, Cornelisse, \& Devilee, 2007).

In the general population, the prevalence of BRCA1/2 mutation carriers is approximately $0.2 \%$. However, the prevalence varies considerably among countries or ethnic groups. BRCA1/2 mutations are most prevalent among the Ashkenazi Jewish population. People of Ashkenazi Jewish ancestry have a 10-fold higher prevalence than the general population (where 1 in 40 (2.6\%) people carries a BRCA1/2 mutation). Ashkenazi people are currently living worldwide and are centered mainly in countries in Central and Eastern Europe such as Poland, Lithuania, Belarus, Germany, Hungary, Ukraine and Russia (Janavičius, 2010).

Personal history of breast cancer increases the risk of having new cancer. A book written by Jane Plant concerning prevention and treatment of breast and ovarian cancer states that women who have previously been diagnosed with breast cancer are 3 to 4 times more likely to develop new cancer either in another part of the same breast or in the other breast (Plant, 2007). Furthermore, a study was conducted to examine the accuracy and outcomes of mammography screening in females with a personal history of early-stage breast cancer. This study found that women with a personal history of breast cancer have about twice the risk of developing breast cancer within 1 year compared to women without a personal history of breast cancer (Houssami et al., 2011). In addition, women with benign breast disease, high dense breast tissue, and higher endogenous estrogen levels in the blood have been associated with an increased risk of developing breast cancer (Kamińska, Ciszewski, Łopacka-Szatan, Miotła, \& Starosławska, 2015).

Furthermore, family history of breast cancer substantially rises the risk. This depends on several factors including the age of the female, the number of affected relatives, and the generational distance of the affected relatives. Compared to females without a family history, breast cancer risk is nearly 2 times higher for females with one first-degree relative (mother, sister, and daughter) who has been previously diagnosed, about 3 times higher for females with two relatives, and almost 4 times higher for females with three or more relatives. The risk for breast cancer linked to a family history of the disease decreases with age (Collaborative Group on Hormonal Factors in Breast Cancer [CGHFBC], 2001).

\subsubsection{Reproductive Factors}

A meta-analysis of a large number of epidemiological studies found that breast cancer risk increases about 5 percent for each year earlier menstruation starts. Moreover, the disease risk rises around 3 percent for each year delay to reach menopause. For instance, breast cancer risk is approximately 20 percent higher among girls who start menstruating before 11 years of age compared to those who start at 13 years of age. With regards to menopause, females who experience menopause at 55 years of age or older have around a 12 percent higher risk compared to those who experience it between 50-54 years of age (CGHFBC, 2012).

Having children later in life or not having children is associated with increased risk of the disease. However, having a first child at a young age and having a large number of children is associated with reduced risk. Britt, Ashworth, and Smalley (2007) state that females having a first child before 20 years of age have a 50 percent lower lifetime risk of breast cancer compared to females who have no children.

According to the Organization for Economic Co-operation and Development, in the most European countries, the average age of women at first childbirth is 30 or older (OECD, 2016). Furthermore, the global average fertility rate is 2.5 children per female, and Europe has the lowest fertility worldwide of 1.6 children per women (United Nations Population Division, 2015).

Brynhildsen (2014) states that the knowledge about the association between recent use of oral contraceptives (combined hormonal pills) and breast cancer is to a great extent still based on the results from the meta-analysis conducted in 1996 by CGHFBC. The main finding in this study was that recent users of oral contraceptives had slightly increased the risk of developing the diseases, particularly among females who started before the age of 20 or before the first pregnancy, and this slight increase vanished ten years after cessation. However, different sources of bias have been discussed about this study. During the last decade, a number of new studies have been published 
regarding this association. Gierisch et al. (2013) found in their systematic review a small but significant increase in risk during ongoing use of oral contraceptives and no association was reported between risk and duration of use. Like in the CGHFBC study, there was no increased risk 10 years after cessation.

Among the well-studied reproductive factors that have been proven to reduce the risk of breast cancer is breastfeeding. According to a recent systematic review and meta-analysis, mothers who breastfeed for twelve months or more have around 26 percent lower risk of developing breast cancer compared to women who have never done so (Chowdhury et al., 2015). Breastfeeding for a longer period of time is associated with a larger risk reduction. A review of 47 epidemiological studies in 30 countries found that the risk of breast cancer is decreased by 4 percent for every year of breastfeeding (CGHFBC, 2002).

\subsubsection{Hormonal Factors}

Higher levels of certain endogenous sex hormones, also known as sex steroids, are associated with an increased breast cancer risk. Sex steroids include progesterone, estrogen, and testosterone (Endogenous Hormones and Breast Cancer Collaborative Group [EHBCCG], 2011). Postmenopausal females with high levels of endogenous sex hormones, including oestradiol, testosterone and, androstenedione, have about a two-fold higher risk of developing breast cancer, compared with women with lower levels. In premenopausal women, it is harder to study the association between hormones and breast cancer because hormonal levels (estrogens and progesterone) vary during the menstrual cycle. Nevertheless, a recent study conducted by EPIC found that premenopausal women with the highest serum testosterone levels have a higher risk compared to women with the lowest levels. However, no association was found with other sex hormones (Kaaks et al., 2014). In addition, a pooled analysis of 17 prospective studies has found that the insulin-like growth factor 1 (IGF-1) is positively associated with breast cancer risk in both premenopausal and postmenopausal females (EHBCCG, 2010).

Furthermore, an observational study has shown that the recent use of menopausal hormones (hormone replacement therapy), combined with progestin and estrogen, increases the risk of having breast cancer. The same study has also found that the risk is higher with a longer duration of use. Additionally, females who begin hormone therapy closer to the onset of menopause have a higher risk of developing the disease than women who initiate the use later (Chlebowski et al., 2013). The increased risk seems to decrease within five years after cessation of hormone use (Beral, Reeves, Bull, Green, \& Collaborators, 2011).

\subsubsection{Lifestyle Factors}

\subsubsection{Body Weight}

The association between excess body weight and breast cancer risk differs based on menopausal status. La Vecchia, Giordano, Hortobagyi, and Chabner (2011) concluded in their study that excess body fat increases the risk of developing postmenopausal breast cancer. The risk is around 1.5 times higher in overweight females and around 2 times higher in obese females compared with normal weight females. They also found that this association is stronger in elderly women. The increased risk of postmenopausal breast cancer associated with the excess body fat is probably due to the increased formulation of estrogen from precursor hormones in the fat tissue (R. C. Travis \& Key, 2003). This association could also be due to the higher levels of insulin in obese females. Obesity is also a risk factor for type 2 diabetes, which has been independently linked to an increased risk for postmenopausal breast cancer. A meta-analysis of 40 observational epidemiological studies found that the risk of postmenopausal breast cancer in females with type 2 diabetes is increased by 16 percent (Boyle et al., 2012).

The average rate of postmenopausal breast cancer in European women attributable to obesity is approximately 34.3 percent compared to the total number of all such attributable cases (Table 2).

Table 2. Postmenopausal breast cancer cases in 2012 in European women who attributable to excess (BMI) by region compared to total number of all such attributable cases

\begin{tabular}{lll}
\hline Region & Number of cases & Percentage (\%) \\
\hline Eastern Europe & 13337 & $26 \%$ \\
Northern Europe & 7513 & $38 \%$ \\
Western Europe & 14582 & $39 \%$ \\
Southern Europe & 9096 & $34 \%$ \\
\hline
\end{tabular}


Adapted from "Cancer and Obesity: Global burden of cancer attributable to excess weight", by Arnold, M., Lam, F., Ervik, M., \& Soerjomataram, I., (2015). Retrieved from http://gco.iarc.fr/obesity

In contrast, several studies have shown that there is an inverse association between obesity and premenopausal breast cancers. A meta-analysis of breast cancer risk factors among females between 40 and 49 years of age established that the risk for having breast cancer was around 14 percent and 26 percent lower in overweight and obese females respectively compared to females who were normal weight (Nelson et al., 2012). Nonetheless, the lifestyle adjustments of women to minimize the risks of developing breast cancer usually includes avoiding being overweight and decreasing intake of fats (Engin, 2017).

Many studies have examined whether the timing of weight gain effects breast cancer risk. A study conducted by EPIC concluded that weight gain in middle adulthood (women aged 40-50 years) increased the risk of breast cancer. This association was more pronounced for breast cancer diagnosed before or at 50 years of age (Emaus et al., 2014). Moreover, a meta-analysis found that each $5 \mathrm{~kg}$ gained during adulthood rises the risk of breast cancer among postmenopausal women by 11 percent. This positive relationship was only observed among females who did not use menopausal hormones (Keum et al., 2015).

\subsubsection{Physical Activity}

Numerous studies have suggested that women who get regular physical activity have a lower risk of developing breast cancer compared to women who are inactive (Wu, Zhang, \& Kang, 2013). A study done by EPIC showed that moderate and high levels of physical activity, combining recreational and household activities, were independently associated with a decreased risk of both premenopausal and postmenopausal breast cancer (Steindorf et al., 2013). The underling mechanisms of this reduced risk are the effects of physical activity on body weight, energy balance, and hormones (Neilson, Friedenreich, Brockton, \& Millikan, 2009).

According to estimates from the Lancet Physical Activity Series Working Group, 9 percent of breast cancer cases in Europe are attributable to inadequate physical activity levels. Data differ among European countries, ranging from 4 percent of breast cancer cases in the Netherlands and Greece to 19 percent of breast cancer cases in Malta and Serbia, which could be prevented by sufficient levels of physical activity (Lee et al., 2012).

\subsubsection{Diet}

Many studies have looked at the relationship between diets, such as fat, fruit and vegetables, dairy, meat, and fiber, and breast cancer. EPIC conducted a study examining the association between dietary fat and breast cancer risk. The main finding was that high saturated fat increased the risk of breast cancer. This positive association was more pronounced among postmenopausal females who never used hormone therapy. No significant association was found in this study between monounsaturated, and polyunsaturated fat (Sieri et al., 2008). A meta-analysis study showed that the risk of breast cancer is 13 percent higher among females with the highest total fat consumption compared with women with the lowest fat intake (Boyd et al., 2003).

Many studies have confirmed the positive association between alcohol intake and breast cancer risk. A recent study conducted by EPIC found that for each $10 \mathrm{~g} /$ day increase in alcohol consumption, the breast cancer risk increased by 4.2 percent. Alcohol consumption of $>5$ to $15 \mathrm{~g}$ /day was linked to a 5.9 percent rise in breast cancer risk. The association was stronger among females who begun drinking before their first full-term pregnancy (Romieu et al., 2015).

Seitz, Pelucchi, Bagnardi, and Vecchia (2012) reported that out of the approximately 50,000 cases of breast cancer attributed to alcohol intake globally, around 5\% are found in Northern Europe and North America. This research estimated that around $2 \%$ of the breast cancers cases in Europe and North America are attributable to light drinking. Seitz et al. (2012) argue that the mechanism by which alcohol is considered a risk factor is that it results in increased estrogen levels, facilitating the carcinogenic effects of estrogens on the breast tissue. Other mechanisms by which alcohol can play a role may include "acetaldehyde, oxidative stress, epigenetic changes due to a disturbed methyl transfer and decreased retinoic acid concentrations associated with an altered cell cycle" (Seitz et al., 2012).

In contrast, many studies have found inverse associations between certain diets and breast cancer. A meta-analysis of prospective studies showed that high consumption of fruit and vegetables lined to a weak reduction of breast cancer risk (Aune et al., 2012). Dietary fiber is also related to decreased risk. Indeed, a large EPIC study has shown that high consumption of dietary fiber reduced the breast cancer risk (Ferrari et al., 2013).

\subsubsection{Tobacco}

Studies have examined the relationship between tobacco smoking and breast cancer. A recent meta-analysis of 
observational studies indicated that both active and passive smoking were associated with a modest but significant increase in breast cancer risk (Macacu, Autier, Boniol, \& Boyle, 2015). Several studies have investigated whether different factors related to smoking, such as the timing and frequency of smoking, affect the breast cancer risk. A study conducted in EPIC cohort found that the positive association between smoking and the disease was higher among women who started smoking from menarche to before their first birth (Dossus et al., 2014). Additionally, a higher risk was observed among long-term and heavy smokers (EHBCCG, 2011).

\subsubsection{Environmental Factors}

\subsubsection{Radiation}

Gamma-radiation and X-radiation are classified by the IARC as causes of breast cancer (IARC, 2017). A review of epidemiological studies examining the association between ionizing radiation exposure and breast cancer risk found that there was a linear relationship. The amount of risk depends strongly on when radiation exposure occurs. Women who have been exposed to radiation before 20 years of age carry the greatest risk (Ronckers, Land, \& Erdmann, 2004). This can be related to the fact that the breast tissue is most susceptible to carcinogens before it is fully differentiated. Full differentiation of the breast tissue occurs with the first childbirth (Russo, Hu, Yang, \& Russo, 2000).

Also, girls and females who had high-dose radiation to the chest between the age of 10 and 30 to treat another disease, such as Hodgkin disease, are at increased risk for breast cancer (Clemons, Loijens, \& Goss, 2000). Breast cancer risk in females with such exposure begins to increase around 8 years after radiation treatment and continues to be high for more than 25 years (L. B. Travis et al., 2003).

\subsubsection{Occupational Exposures}

A few occupations have been linked to breast cancer risk. Occupational exposure to ethylene oxide is classified based on limited evidence by the IARC as a probable cause of breast cancer (IARC, 2017). A cohort study conducted in Swedish sterilant workers exposed to ethylene oxide found that the risk of breast cancer is about 2 to 3 times higher in the most exposed workers compared with the lowest exposed (Mikoczy, Tinnerberg, Björk, \& Albin, 2011). Night shift work has also been classified by the IARC as a probable cause of breast cancer (IARC, 2017). A meta-analysis of epidemiological studies found that night shift work increases breast cancer risk by 40 percent (Jia et al., 2013). The disease risk is higher among females with more exposure to artificial light at night (Yang, Deng, Fan, Wang, \& Wang, 2014).

The circadian disruption caused by artificial light at night is linked with the lower production of melatonin. Increased melatonin levels are associated with lower breast cancer risk. Indeed, high levels of melatonin reduce circulating estrogen and thus inhibit tumors from developing or growing (Stevens, Brainard, Blask, Lockley, \& Motta, 2014). This may partly explain the association between shift work and breast cancer risk. However, confounding by other lifestyle factors, such as BMI, tobacco smoking, and physical activity is possible (Jia et al., 2013). Doing night shifts is considered a common exposure, which involves around 15 to 20 percent of the workers in the United States and Europe (American Cancer Society, 2015).

\subsection{EU Policies and Strategies Concerning Breast Cancer}

In general, the EU has responded with more actions on cancer than on any other public health issue until now. During the last three decades, the EU has formulated and enacted different series of cancer control policies and initiatives, as a sign of recognition of the heavy health, emotional and societal burden of cancer. The shift from horizontal "broad-based", as most of the EU health policies and initiatives are, to vertical "narrow-based" programs targeting cancers specifically is considered a response to the high burden of cancers and its high mortality rates. With regards to breast cancer, detection of the disease in its early stage represents the main focus of the EU policies, initiatives and research funding (Breast Cancer Matters, N.G).

\subsubsection{The European Parliament Resolutions on Breast Cancer}

The European Parliament (EP) adopted two Resolutions to combat breast cancer in 2003 and 2006. These Resolutions contain a number of calls on the major political parties, including the Commission, Member States, and the Council. In one EP Resolution from 2003 (A5-0159/2003), the EP stated that fighting against breast cancer should be a health policy priority for both Member States and the European Commission. In addition, it is essential to develop and implement efficient strategies for better preventive health care: screening, diagnosis, treatment, and aftercare in order to attain the highest quality in breast cancer treatment around Europe. The EP also stated that every female, regardless of where she lives, her social status, her occupation, and her educational level, should have access to high-quality screening and treatment for all breast cancer stages. Apart from other calls on the 
Member States, the EP sought to decrease breast cancer deaths by 25 percent and the rate of disparity among the Member States in the five-year survival by 5 percent, to be achieved by 2008. Additionally, the EP sought to allocate more Structural Fund resources to finance health care system investments, in order to minimize regional disparities in access to breast cancer care (European Parliament, 2003).

In the 2006 EP Resolution on Breast Cancer (B6/0528/2006), the EP reinforced the demands stipulated in the first Resolution. It called on the European Commission to present the progress reports on the implementation of breast cancer screening programs, as well as the steps taken by the Member States to reduce breast cancer death rates, as set out in the Resolution of 2003. The Resolution calls on the Member States to "Ensure nationwide provision of interdisciplinary breast units in accordance with the EU guidelines by 2016 since treatment in an interdisciplinary breast unit has been proved to raise chances of survival and to improve the quality of life and calls on the Commission to deliver a progress report on this every two years". It also sets new instructions, which includes strengthening research on the topic, ensuring job security and protection for breast cancer patients, and establishing European directives for breast care nurses (European Parliament, 2006).

The EP Resolutions underscores the necessity of mammography screening, treatment and set up of breast units based on the European guidelines. These include the right of women between the ages of 50 and 69 to attend high-quality mammography screening every two years, which is to be done in dedicated and certified centers, and is covered by health insurance schemes.

\subsubsection{European Guidelines for Quality Assurance in Breast Cancer Screening and Diagnosis}

In 2006, the European Commission (EC), in cooperation with the European Reference Organization for Quality Assured Breast Screening and Diagnostic Services (EUREF), the European Breast Cancer Network (EBCN), and the European Society of Mastology (EUSOMA) published the 4th edition of the European Guidelines for Quality Assurance in Breast Cancer Screening and Diagnosis. The main goals of these guidelines were to raise quality standards and procedures at EU level, by presenting the best examples from local and national breast cancer mammography-based screening programs over the previous 20 years, as well as to guarantee the quality of breast cancer services in general. These guidelines can be used as a manual for professionals and advocates working in the health sector worldwide. The European Guidelines were prepared by over 200 professionals and contributors. The document also emphasizes the importance of breast cancer screening in the reduction of the disease's morbidity and mortality. It also states that breast cancer screening is a complex multidisciplinary project that requires experienced and trained professionals using the specialized and advanced equipment. Among the essential points in the European Guidelines are the following: all specialist breast units implementing screening, diagnosis or assessment are obliged to work based on the protocols agreed upon, which are based on national or European documents that contain acknowledged clinical standards and published values. The differences in practices and healthcare environments across the member states of the European Union are not to interfere with the application of these protocols. Furthermore, specialist breast centers are required to ensure the formation of a competent multidisciplinary team, which involves a full range of specially trained professionals including a radiologist, a radiographer, a pathologist, a surgeon, a nurse counselor and a medical oncologist/radiotherapist.

Other fundamental aspects of this European Guidelines are ensuring high-quality programs by setting requirements for effective training and communication. The guidelines state that all stuff working in screening programs should hold professional qualifications, follow a specialist training, take part in continuing medical education and updates, participate in acknowledged external quality assessment schemes, and hold the necessary certificates of competence. Also, sufficient information is needed to be provided and it should be presented in an unbiased and proper way to facilitate a fully informed decision as to whether to participate or not. Communication is a fundamental part of all processes of breast cancer care and this should be effective between health care providers and patients. The information given should be evidence-based, honest, balanced, accessible, and accustomed to individual needs as much as possible.

Monitoring and evaluation activities must be carried out throughout breast cancer programs. Audit system on Quality of breast cancer diagnosis and Treatment (QT) is a tool that was developed for and is being utilized by clinical breast centers, in order to monitor diagnosis and treatment of breast lesions in patients, whether it is in symptomatic or asymptomatic females. To achieve such a goal, the evaluation of the effect of screening demands: the complete and accurate recording of all individual data that relate to the target population, the screening test used, the results of screening, the decisions made accordingly, as well as the outcome in both diagnosis and treatment (Perry et al., 2008). 


\subsubsection{European Commission Initiative on Breast Cancer}

The EC launched an Initiative on Breast Cancer (ECIBC) project in 2012. The ECIBC is coordinated by a Commission's Joint Research Centre (JRC) under the administration of the Directorate-General for Health and Food Safety (DG SANTE). The forces behind the adoption of such a project were the ongoing burden of breast cancer in Europe, as well as the substantial inequalities that exist within European countries with relation to breast cancer. The overall aim of this project was to improve population health and to reduce health inequalities in Europe by guaranteeing the quality of breast cancer services. The four main objectives of this project are:

1) Offering evidence-based recommendations for breast cancer services in five stages. This was intended to be done by the development of a new version of the European Guidelines covering breast cancer screening and diagnosis and, in addition, the establishment of a Platform Guidelines covering treatment, rehabilitation, and follow-up stages.

2) The development of a European Quality Assurance (QA) scheme for breast cancer services based on EU legislation.

3) The development of a European training template on digital mammography for screening.

4) The development of a long-term web hub offering all the outputs, tools, and information regarding breast cancer (European Commission, 2015).

\subsubsection{European Breast Cancer Conference}

The European Breast Cancer Conference (EBCC) is a regularly upheld conference, once every two years and the first of these conferences was held in Florence in 1998. The conference is organized by the European Breast Cancer Council (EBC). The EBC is formed of different European bodies including the European Society of Breast Cancer Specialists (EUSOMA), EORTC Breast Cancer Group (EORTC-BCG) and EUROPA DONNA.

The aims of the European Breast Cancer Conferences are:

- Promoting the establishment of European scientific exchange multidisciplinary platforms concerned with breast cancer.

- Facilitating the spread of scientific research results among the different bodies of the council.

- Promoting patients to have equal access to quality treatment, as well as promoting for breast cancer researches.

- Supporting the communication and networks between the public and the patients and providing them with the best scientific information available (European Breast Cancer Council, 2017).

\subsubsection{European Code Against Cancer}

The European Code against Cancer is an initiative of the EC. It is based on the conviction that population health can be improved, and certain cancers can be prevented, by adopting healthier lifestyle activities. The first edition of the initiative was issued in 1987. The current fourth edition was made by a multidisciplinary team of cancer specialists, scientists and other experts from the EU in 2012-2013, and it was coordinated by the IARC. The content of the Code is based on the latest scientific evidence available.

This initiative was established to inform individuals about actions they can take for themselves or their families to lower their cancer risk. The last edition presents twelve recommendations which people could follow to decrease their own risk. The more such recommendations are followed, the lower is the risk of developing the disease. Indeed, it was estimated that around fifty percent of deaths attributable cancer in Europe might be avoided if populations were to adhere to the following recommendations set by the initiative:

1) Avoiding smoking, and any form of tobacco types.

2) Making home and workplace smoke-free

3) Taking action to have a healthy body weight

4) Being physically active daily. minimize the time spent sitting

5) Having a healthy diet by consuming plenty of fruits and vegetables, pulses, and whole grains. Liming high-calories food, red meat, and high-sodium foods. Avoiding sugary beverages and processed meat.

6) Limiting alcohol intake, Cessation of alcohol drinking is associated with fewer chances of developing cancer

7) Avoiding too much exposure to sun, particularly for children, and using sun protection. 
8) Following health and safety guidelines at workplaces to avoid cancer-causing substances

9) Reducing exposure to high amounts of ionizing radiation at home

10) For women: breastfeeding and limiting the use of hormonal replacement therapy.

11) Getting vaccinations against hepatitis B virus infection, and human papillomavirus.

12) Participating in bowel, breast, and cervical cancer screening programs (Schüz et al., 2015).

\section{Discussion}

The present study was aimed at assessing the prevalence and risk factors of breast cancer in the EU countries, and how have those evidences been translated into health policies at the EU level. It was found abundant evidence that the prevalence of breast cancer in the EU is the highest compared to the other regions in the world (EUROPA DONNA, 2015). Such high prevalence can be explained by the fact that the life expectancy in the EU is one of the highest in the world, especially when compared to Africa and south-east Asia and aging is one of the unmodifiable risk factors for breast cancer. Other reasons include the advancement in medical diagnostic techniques in the EU compared to most of the other regions, where such diagnostic tools may not be available or be too expensive to be used for screening, and as a result, patients can die of breast cancer without being diagnosed with it (Youldent et al., 2012).

Trends in breast cancer incidence and mortality from the late 1980s to the early 2000s resulted from a variety of influences. Autier et al. (2010) have suggested that these considerable disparities between European countries are generally attributed to mortality levels in the late 1980s, large changes in the prevalence of the breast cancer risk factors, as well as mammography screening, and availability and acceptance of effective treatment strategies. Highest reductions in breast cancer mortality were results of combining high nation-wide participation in screening programs, rapid adoption and easily accessible medical services, and use of multidisciplinary approach in breast health-care services. This was seen in England as an example. On the other hand, countries, including central and eastern European countries, which failed to implement organized screening programs, had relatively slow uptake of anticancer medicines, and have below-European-average health expenditure, witnessed an increase in mortality rates of breast cancer. Another possible explanation is that, following the collapse of communism in those countries, rapid changes in the risk factors of breast cancer, such as decreased fertility and older age at first birth, played a role. (Autier et al., 2010).

Several studies have found that women of European descent have a remarkably higher risk of developing breast cancer compared with women from other racial-ethnic groups (Fejerman et al., 2010; Jing et al., 2014). In addition, previous studies have attributed the high incidence rate among white females to the lifestyle and socioeconomic status (Lundqvist et al., 2016). Higher socioeconomic status was associated with higher incidence rate. This is due to the ability of women who are of high SES to afford the screening for breast cancer. In addition, the lifestyle for those of high SES can pose a risk. Further, women of high SES are able to afford hormone replacement therapy which is considered a risk cancer for breast cancer (EHBCCG, 2011). Also, the age at first delivery and the duration of breastfeeding have their implications on developing breast cancer. Women in the EU tend to have their first baby at an age average of around 30 years (OECD, 2016), which increases the risk of developing breast cancer. An additional risk factor that might be of more prominence in the western world is the short period or total lack of breastfeeding. There are some possible explanations for this phenomenon. One is that women who breastfeed have less number of menstrual cycles throughout their lives, which means lower estrogen levels. Another possible explanation is lactation makes breast cells more resistant to mutations. In addition, women who breastfeed tend to eat nutritious foods and adopt healthier lifestyle choices (BREASTCANCER.ORG, 2013). Nevertheless, the mortality rate of breast cancer is relatively lower in Europe when compared globally. That because they can afford the costs of treatment alongside the availability of the different treatment options in the western world, compared to the rest of the females around the globe.

Acknowledging the risk of breast cancer and its increasing incidence, the EU has drafted policies focused on the disease, and on the ways to tackle its adverse outcomes. The EP has drafted two policies which specifically address breast cancer (European Parliament, 2003; European Parliament, 2006). The policies stated that all women in the EU countries should have access to high-quality diagnosis and treatment options for breast cancer, regardless of their socioeconomic status. Therefore, the policies focused on setting up the needed requirements for diagnosing and managing breast cancer across the EU countries. It also underscored the importance of regular two-year intervals breast cancer screening for women aged 50 or more, which represents the group at highest risk.

Furthermore, in 2006, the EC and other EU bodies have developed guidelines that would raise the quality of the procedures related to breast cancer diagnosis and treatment (European Commission, 2006). These guidelines were 
to be implemented on a national level in the EU, but they became a framework for breast cancer protocol around the globe. Following that, in 2012, the EC started its initiative on breast cancer (ECIBC) that reflected the burden of the disease in the region. The initiative focused on developing a European quality assurance scheme for the breast cancer services across the EU, as well as providing a training template for the screening programs, and setting up a regional network to share related information. The $\mathrm{EC}$ has also provided recommendations that would reduce the incidence of breast cancer by $50 \%$, if followed carefully.

The difference in the incidence and mortality rates across the different regions in Europe raise questions about how the policies of the EU are applied on national levels. The difference in incidence across the different regions of the EU can be attributed to the difference in lifestyle and reproductive factors, while the difference in mortality rates underscores the difference in the detection and treatment options differences across the different regions. As a result, the EU needs to re-evaluate the policies concerned with breast cancer detection and management across the different EU countries.

All of these efforts reflect the attention breast cancer received in the EU, but the ongoing high burden of the disease shows that the problem has not been tackled properly yet. The EU has allocated funds, policies and time to tackle the issue before and after the development of the disease by addressing the possible risk factors and life style practices contributing to the disease development, as well as providing the necessary means for diagnosis and treatment. This has been reflected by the decreasing mortality rate and the growth of breast cancer survivors in the EU (Torre et al., 2015). However, more focus should be put on the implementation and follow up of these policies and initiatives, which could assure decreasing the burden of the disease in the region.

\section{Conclusion}

This study highlighted how, due to multiple factors, the prevalence of breast cancer is the highest in Europe. This finding does not only suggest that the region has an abundance of risk factors, especially those which can be modified, but it can also hint that the region has more diagnostic measures in place. It is also worth noting that the disease has some unmodifiable risk factors such as aging and sex (Lewis, Dieksen, Heitkemper \& Butcher, 2013), which may be particularly relevant in the EU as such countries are known for their aging population. The EU has set the policies to tackle the burden of breast cancer in the region, and although these policies have been made with scientific evidence, the burden is still high. This, in turn, reflects the importance of enacting policies, and the continuous process of their monitoring and evaluation. Therefore, we recommend that the EU and its associated parties of interest would review the mechanisms of implementation of the policies on a national level, as well as provide continuous monitoring and support to enacting the policies on a country level and have efficient tools for evaluation and continuous polishing of the policies in place. Such processes could also improve the process of standardization across health services and programs in Europe. This, in turn, may improve health outcomes and would be of great benefit to the population at risk in those regions.

\section{Funding}

None.

\section{Competing Interests Statement}

The authors declare that there are no competing or potential conflicts of interest.

\section{References}

Altobelli, E., \& Lattanzi, A. (2014). Breast cancer in European Union: an update of screening programmes as of March 2014. International journal of oncology, 45(5), 1785-1792. https://doi.org/10.3892/ijo.2014.2632

American Cancer Society. 2015. Breast Cancer Facts \& Figures 2015-2016. Atlanta: American Cancer Society. Retrieved April 30, 2017, from https://www.cancer.org/content/dam/cancer-org/research/cancer-facts-andstatistics/breast-cancer-facts-and-figures/breast-cancer-facts-and-figures-2015-2016.pdf

Arnold, M., Lam, F., Ervik, M., \& Soerjomataram, I. (2015). Cancer and Obesity: Global burden of cancer attributable to excess weight. Lyon, France: International Agency for Research on Cancer. Retrieved May 2, 2017, from http://gco.iarc.fr/obesity

Aune, D., Chan, D., Vieira, A., Rosenblatt, D. N., Vieira, R., Greenwood, D., \& Norat, T. (2012). Fruits, vegetables and breast cancer risk: a systematic review and meta-analysis of prospective studies. Breast cancer research and treatment, 134(2), 479-493. https://doi.org/10.1007/s10549-012-2118-1

Autier, P., Boniol, M., La Vecchia, C., Vatten, L., Gavin, A., Hery, C., \& Heanue, M. (2010). Disparities in breast cancer mortality trends between 30 European countries: retrospective trend analysis of WHO mortality 
database. $B M J, 341$, c3620. https://doi.org/10.1136/bmj.c3620

Beral, V., Reeves, G., Bull, D., Green, J., \& Collaborators, M. W. S. (2011). Breast cancer risk in relation to the interval between menopause and starting hormone therapy. Journal of the National Cancer Institute, 103(4), 296-305. https://doi.org/10.1093/jnci/djq527

Boyd, N., Stone, J., Vogt, K., Connelly, B., Martin, L., \& Minkin, S. (2003). Dietary fat and breast cancer risk revisited: a meta-analysis of the published literature. British Journal of Cancer, 89(9), 1672-1685. https://doi.org/10.1038/sj.bjc.6601314

Boyle, P., Boniol, M., Koechlin, A., Robertson, C., Valentini, F., Coppens, K., . . Pasterk, M. (2012). Diabetes and breast cancer risk: a meta-analysis. British Journal of Cancer, 107(9), 1608-1617. https://doi.org/10.1038/bjc.2012.414

Breast Cancer Matters. (n.d.). European Policy Initiatives on BC/MBC. Retrieved July 15, 2017, from: https://breastcancer-matters.eu/european-policy-initiatives-bcmbc

Britt, K., Ashworth, A., \& Smalley, M. (2007). Pregnancy and the risk of breast cancer. Endocrine-related cancer, 14(4), 907-933. https://doi.org/10.1677/ERC-07-0137

Brown, J. C., Winters - Stone, K., Lee, A., \& Schmitz, K. H. (2012). Cancer, physical activity, and exercise. Comprehensive Physiology. https://doi.org/10.1002/cphy.c120005

Brynhildsen, J. (2014). Combined hormonal contraceptives: prescribing patterns, compliance, and benefits versus risks. Therapeutic advances in drug safety, 5(5), 201-213. https://doi.org/10.1177/2042098614548857

Chlebowski, R. T., Manson, J. E., Anderson, G. L., Cauley, J. A., Aragaki, A. K., Stefanick, M. L., . . Chen, C. (2013). Estrogen plus progestin and breast cancer incidence and mortality in the Women's Health Initiative Observational Study. Journal of the National Cancer Institute, 105(8), 526-535. https://doi.org/10.1093/jnci/djt043

Chowdhury, R., Sinha, B., Sankar, M. J., Taneja, S., Bhandari, N., Rollins, N., . . Martines, J. (2015). Breastfeeding and maternal health outcomes: a systematic review and meta - analysis. Acta Paediatrica, 104(S467), 96-113. https://doi.org/10.1111/apa.13102

Clemons, M., Loijens, L., \& Goss, P. (2000). Breast cancer risk following irradiation for Hodgkin's disease. Cancer treatment reviews, 26(4), 291-302. https://doi.org/10.1053/ctrv.2000.0174

Collaborative Group on Hormonal Factors in Breast Cancer. (2001). Familial breast cancer: collaborative reanalysis of individual data from 52 epidemiological studies including 58209 women with breast cancer and 101986 women without the disease. The Lancet, 358(9291), 1389-1399. https://doi.org/10.1016/S0140-6736(01)06524-2

Collaborative Group on Hormonal Factors in Breast Cancer. (2002). Breast cancer and breastfeeding: collaborative reanalysis of individual data from 47 epidemiological studies in 30 countries, including 50302 women with breast cancer and 96973 women without the disease. The Lancet, 360(9328), 187-195. https://doi.org/10.1016/S0140-6736(02)09454-0

Collaborative Group on Hormonal Factors in Breast Cancer. (2012). Menarche, menopause, and breast cancer risk: individual participant meta-analysis, including 118964 women with breast cancer from 117 epidemiological studies. The lancet oncology, 13(11), 1141-1151. https://doi.org/10.1016/S1470-2045(12)70425-4

Dossus, L., Boutron-Ruault, M. C., Kaaks, R., Gram, I. T., Vilier, A., Fervers, B., . . Overvad, K. (2014). Active and passive cigarette smoking and breast cancer risk: results from the EPIC cohort. International journal of cancer, 134(8), 1871-1888. https://doi.org/10.1002/ijc.28508

EHBCCG. (2011). Circulating sex hormones and breast cancer risk factors in postmenopausal women: reanalysis of 13 studies. British Journal of Cancer, 105(5), 709-722. https://doi.org/10.1038/bjc.2011.254

Emaus, M. J., Van Gils, C. H., Bakker, M. F., Bisschop, C. N. S., Monninkhof, E. M., Travier, N., . . Romieu, I. (2014). Weight change in middle adulthood and breast cancer risk in the EPIC - PANACEA study. International journal of cancer, 135(12), 2887-2899. https://doi.org/10.1002/ijc.28926

Endogenous Hormones and Breast Cancer Collaborative Group. (2010). Insulin-like growth factor 1 (IGF1), IGF binding protein 3 (IGFBP3), and breast cancer risk: pooled individual data analysis of 17 prospective studies. The lancet oncology, 11(6), 530-542. https://doi.org/10.1016/S1470-2045(10)70095-4

Endogenous Hormones and Breast Cancer Collaborative Group. (2011). Circulating sex hormones and breast 
cancer risk factors in postmenopausal women: reanalysis of 13 studies. British journal of cancer, 105(5), 709-722. https://doi.org/10.1038/bjc.2011.254

Engin, A. (2017). Obesity-associated Breast Cancer: Analysis of risk factors Obesity and Lipotoxicity (pp. 571-606). Springer.

European commission. (2015). European Commission Initiative on Breast Cancer: concept document. Retrieved August 10, 2017, from https://www.myesr.org/sites/default/files/ECIBC\%20Concept\%20Document_0.pdf

European commission. (2016). Pilot project - Primary prevention courses for girls living in areas with higher risk of breast cancer. Retrieved April 3, 2017, from http://ec.europa.eu/research/participants/data/ref/other_eu_prog/other/hp/call-fiche/hp-call-fiche-pp2-5_en.p $\mathrm{df}$

European Parliament resolution on breast cancer in the enlarged European Union, (B6/0528/2006) C.F.R. (2006).

European Parliament resolution on breast cancer in the European Union, (A5-0159/2003) C.F.R. (2003).

Fejerman, L., Romieu, I., John, E. M., Lazcano-Ponce, E., Huntsman, S., Beckman, K. B., . . Torres-Mejía, G. (2010). European ancestry is positively associated with breast cancer risk in Mexican women. Cancer $\begin{array}{lllll}\text { Epidemiology and Prevention 1074-1082. } & \text { Biomarkers, }\end{array}$ https://doi.org/10.1158/1055-9965.EPI-09-1193

Ferlay, J., Soerjomataram, I., Ervik, M., Dikshit, R., Eser, S., Mathers, C., ... Bray, F. (2013). GLOBOCAN 2012 v1.0, Cancer Incidence and Mortality Worldwide: IARC CancerBase No. 11 [Internet]. Lyon, France: International Agency for Research on Cancer. Retrieved May 2, 2017, from: http://globocan.iarc.fr.

Ferlay, J., Héry, C., Autier, P., \& Sankaranarayanan, R. (2010). Global burden of breast cancer Breast cancer epidemiology (pp. 1-19): Springer.

Ferlay, J., Soerjomataram, I., Dikshit, R., Eser, S., Mathers, C., Rebelo, M., . . Bray, F. (2015). Cancer incidence and mortality worldwide: sources, methods and major patterns in GLOBOCAN 2012. International journal of cancer, 136(5). https://doi.org/10.1002/ijc.29210

Ferlay, J., Steliarova-Foucher, E., Lortet-Tieulent, J., Rosso, S., Coebergh, J., Comber, H., . . Bray, F. (2013). Cancer incidence and mortality patterns in Europe: estimates for 40 countries in 2012. European journal of cancer, 49(6), 1374-1403. https://doi.org/10.1016/j.ejca.2012.12.027

Ferrari, P., Rinaldi, S., Jenab, M., Lukanova, A., Olsen, A., Tjønneland, A., . . Touillaud, M. (2013). Dietary fiber intake and risk of hormonal receptor-defined breast cancer in the European Prospective Investigation into Cancer and Nutrition study. The American journal of clinical nutrition, 97(2), 344-353. https://doi.org/10.3945/ajcn.112.034025

Fitzmaurice, C., Allen, C., Barber, R. M., Barregard, L., Bhutta, Z. A., Brenner, H., .. . Dandona, L. (2017). Global, regional, and national cancer incidence, mortality, years of life lost, years lived with disability, and disability-adjusted life-years for 32 cancer groups, 1990 to 2015: a systematic analysis for the global burden of disease study. JAMA oncology, 3(4), 524-548. https://doi.org/10.1001/jamaoncol.2016.5688

Gierisch, J. M., Coeytaux, R. R., Urrutia, R. P., Havrilesky, L. J., Moorman, P. G., Lowery, W. J., . . Sanders, G. D. (2013). Oral contraceptive use and risk of breast, cervical, colorectal, and endometrial cancers: a systematic review. Cancer Epidemiology and Prevention Biomarkers, 22(11), 1931-1943. https://doi.org/10.1158/1055-9965.EPI-13-0298

Holleczek, B., Arndt, V., Stegmaier, C., \& Brenner, H. (2011). Trends in breast cancer survival in Germany from 1976 to 2008-a period analysis by age and stage. Cancer epidemiology, 35(5), 399-406. https://doi.org/10.1016/j.canep.2011.01.008

Houssami, N., Abraham, L. A., Miglioretti, D. L., Sickles, E. A., Kerlikowske, K., Buist, D. S., . . Irwig, L. (2011). Accuracy and outcomes of screening mammography in women with a personal history of early-stage breast cancer. Jama, 305(8), 790-799. https://doi.org/10.1001/jama.2011.188

International Agency for Research on Cancer. (2016). CANCER FACT SHEETS: BREAST CANCER [Fact sheet]. Retrieved from http://gco.iarc.fr/today/data/pdf/fact-sheets/cancers/cancer-fact-sheets-15.pdf

International Agency for Research on Cancer. (2017). List of Classifications by cancer sites with sufficient or limited evidence in humans, Volumes 1 to 119. Retrieved July 15, 2017, from http://monographs.iarc.fr/ENG/Classification/index.php 
Janavičius, R. (2010). Founder BRCA1/2 mutations in the Europe: implications for hereditary breast-ovarian cancer prevention and control. EPMA journal, 1(3), 397-412. https://doi.org/10.1007/s13167-010-0037-y

Jia, Y., Lu, Y., Wu, K., Lin, Q., Shen, W., Zhu, M., . . Chen, J. (2013). Does night work increase the risk of breast cancer? A systematic review and meta-analysis of epidemiological studies. Cancer epidemiology, 37(3), 197-206. https://doi.org/10.1016/j.canep.2013.01.005

Jing, L., Su, L., \& Ring, B. Z. (2014). Ethnic background and genetic variation in the evaluation of cancer risk: a systematic review. PloS one, 9(6), e97522. https://doi.org/10.1371/journal.pone.0097522

Kaaks, R., Tikk, K., Sookthai, D., Schock, H., Johnson, T., Tjønneland, A., . . Dossus, L. (2014). Premenopausal serum sex hormone levels in relation to breast cancer risk, overall and by hormone receptor status-results from the EPIC cohort. International journal of cancer, 134(8), 1947-1957. https://doi.org/10.1002/ijc.28528

Kamińska, M., Ciszewski, T., Łopacka-Szatan, K., Miotła, P., \& Starosławska, E. (2015). Breast cancer risk factors. Przeglad menopauzalny= Menopause review, 14(3), 196. https://doi.org/10.5114/pm.2015.54346

Keum, N., Greenwood, D. C., Lee, D. H., Kim, R., Aune, D., Ju, W., . . Giovannucci, E. L. (2015). Adult weight gain and adiposity-related cancers: a dose-response meta-analysis of prospective observational studies. Journal of the National Cancer Institute, 107(2), djv088. https://doi.org/10.1093/jnci/djv088

Krugg, E., Dahlberg, L., Mercy, J., Zwi, A., \& Lozano, R. (2002). Violence-a global public health approach. World report on violence and health: Geneva, Switz: World Health Organization.

La Vecchia, C., Giordano, S. H., Hortobagyi, G. N., \& Chabner, B. (2011). Overweight, obesity, diabetes, and risk of breast cancer: interlocking pieces of the puzzle. The oncologist, 16(6), 726-729. https://doi.org/10.1634/theoncologist.2011-0050

Lee, I.-M., Shiroma, E. J., Lobelo, F., Puska, P., Blair, S. N., Katzmarzyk, P. T., \& Group, L. P. A. S. W. (2012). Effect of physical inactivity on major non-communicable diseases worldwide: an analysis of burden of disease and life expectancy. The Lancet, 380(9838), 219-229. https://doi.org/10.1016/S0140-6736(12)61031-9

Lewis, S. L., Dirksen, S. R., Heitkemper, M. M., \& Bucher, L. (2013). Medical-Surgical Nursing: Assessment and Management of Clinical Problems. Single Volume: Elsevier/Mosby.

Luengo-Fernandez, R., Leal, J., Gray, A., \& Sullivan, R. (2013). Economic burden of cancer across the European Union: a population-based cost analysis. The lancet oncology, 14(12), 1165-1174. https://doi.org/10.1016/S1470-2045(13)70442-X

Lundqvist, A., Andersson, E., Ahlberg, I., Nilbert, M., \& Gerdtham, U. (2016). Socioeconomic inequalities in breast cancer incidence and mortality in Europe-a systematic review and meta-analysis. The European Journal of Public Health, 26(5), 804-813. https://doi.org/10.1093/eurpub/ckw070

Macacu, A., Autier, P., Boniol, M., \& Boyle, P. (2015). Active and passive smoking and risk of breast cancer: a

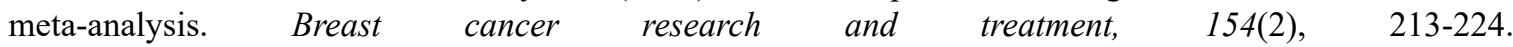
https://doi.org/10.1007/s10549-015-3628-4

McCloskey, D. J., McDonald, M. A., \& Cook, J. (2013). Community engagement: definitions and organizing concepts from the literature.

Mikoczy, Z., Tinnerberg, H., Björk, J., \& Albin, M. (2011). Cancer incidence and mortality in Swedish sterilant workers exposed to ethylene oxide: updated cohort study findings 1972-2006. International journal of environmental research and public health, 8(6), 2009-2019. https://doi.org/10.3390/ijerph8062009

Neilson, H. K., Friedenreich, C. M., Brockton, N. T., \& Millikan, R. C. (2009). Physical activity and postmenopausal breast cancer: proposed biologic mechanisms and areas for future research. Cancer Epidemiology and Prevention Biomarkers, 18(1), 11-27. https://doi.org/10.1158/1055-9965.EPI-08-0756

Nelson, H. D., Zakher, B., Cantor, A., Fu, R., Griffin, J., O'meara, E. S., . . Trentham-Dietz, A. (2012). Risk Factors for Breast Cancer for Women Aged 40 to 49 YearsA Systematic Review and Meta-analysis. Annals of internal medicine, 156(9), 635-648. https://doi.org/10.7326/0003-4819-156-9-201205010-00006

Oldenburg, R., Meijers-Heijboer, H., Cornelisse, C., \& Devilee, P. (2007). Genetic susceptibility for breast cancer: how many more genes to be found? Critical reviews in oncology/hematology, 63(2), 125-149. https://doi.org/10.1016/j.critrevonc.2006.12.004

Perry, N., Broeders, M., de Wolf, C., Törnberg, S., Holland, R., \& von Karsa, L. (2008). European guidelines for 
quality assurance in breast cancer screening and diagnosis—summary document. Annals of Oncology, 19(4), 614-622. https://doi.org/10.1093/annonc/mdm481

Plant, J. A. (2007). Your life in your hands: Understand, prevent and overcome breast cancer and ovarian cancer: Random House.

Porter, P. L. (2009). Global trends in breast cancer incidence and mortality. Salud publica de Mexico, 51, s141-s146. https://doi.org/10.1590/S0036-36342009000800003

Romieu, I., Scoccianti, C., Chajès, V., De Batlle, J., Biessy, C., Dossus, L., . . Olsen, A. (2015). Alcohol intake and breast cancer in the European prospective investigation into cancer and nutrition. International journal of cancer, 137(8), 1921-1930. https://doi.org/10.1002/ijc.29469

Ronckers, C. M., Land, C. E., \& Erdmann, C. A. (2004). Radiation and breast cancer: a review of current evidence. Breast Cancer Research, 7(1), 21. https://doi.org/10.1186/bcr970

Russo, J., Hu, Y.-F., Yang, X., \& Russo, I. H. (2000). Chapter 1: Developmental, cellular, and molecular basis of $\begin{array}{llll}\text { human breast } & \text { cancer. }\end{array}$ https://doi.org/10.1093/oxfordjournals.jncimonographs.a024241

Schüz, J., Espina, C., Villain, P., Herrero, R., Leon, M. E., Minozzi, S., . . Wiseman, M. (2015). European Code against Cancer 4th Edition: 12 ways to reduce your cancer risk. Cancer epidemiology, 39, S1-S10. https://doi.org/10.1016/j.canep.2015.05.009

Seitz, H. K., Pelucchi, C., Bagnardi, V., \& Vecchia, C. L. (2012). Epidemiology and pathophysiology of alcohol and breast cancer: Update 2012. Alcohol and alcoholism, 47(3), 204-212. https://doi.org/10.1093/alcalc/ags011

Sieri, S., Krogh, V., Ferrari, P., Berrino, F., Pala, V., Thiébaut, A. C., . . Jakobsen, M. U. (2008). Dietary fat and breast cancer risk in the European Prospective Investigation into Cancer and Nutrition. The American journal of clinical nutrition, 88(5), 1304-1312.

Steindorf, K., Ritte, R., Eomois, P. P., Lukanova, A., Tjonneland, A., Johnsen, N. F., . . Fournier, A. (2013). Physical activity and risk of breast cancer overall and by hormone receptor status: the European prospective investigation into cancer and nutrition. International journal of cancer, 132(7), 1667-1678. https://doi.org/10.1002/ijc.27778

Stevens, R. G., Brainard, G. C., Blask, D. E., Lockley, S. W., \& Motta, M. E. (2014). Breast cancer and circadian disruption from electric lighting in the modern world. CA: a Cancer Journal for Clinicians, 64(3), 207-218. https://doi.org/10.3322/caac.21218

The Organisation for Economic Co-operation and Development. (2016). SF2.3 Age of mothers and age-specific fertility. Retrieved from http://www.oecd.org/social/family/database.htm

Torre, L. A., Bray, F., Siegel, R. L., Ferlay, J., Lortet - Tieulent, J., \& Jemal, A. (2015). Global cancer statistics, 2012. CA: a Cancer Journal for Clinicians, 65(2), 87-108. https://doi.org/10.3322/caac.21262

Travis, L. B., Hill, D. A., Dores, G. M., Gospodarowicz, M., van Leeuwen, F. E., Holowaty, E., . . Lynch, C. F. (2003). Breast cancer following radiotherapy and chemotherapy among young women with Hodgkin disease. Jama, 290(4), 465-475. https://doi.org/10.1001/jama.290.4.465

Travis, R. C., \& Key, T. J. (2003). Oestrogen exposure and breast cancer risk. Breast Cancer Research, 5(5), 239. https://doi.org/10.1186/bcr628

Tulchinsky, T. H., \& Varavikova, E. A. (2010). What is the "new public health"? Public Health Reviews, 32(1), 25. https://doi.org/10.1007/BF03391592

United Nations, Department of Economic and Social Affairs, Population Division. (2015). World Fertility Patterns 2015-Data Booklet (ST/ESA/SER.A/370)

World Health Organization. (2013). Health 2020. A European policy framework and strategy for the 21st century, Copenhagen, WHO Regional Office for Europe.

World Health Organization. (2015). The top 10 causes of death [Fact sheet]. Retrieved April 30, 2017, from: http://www.who.int/mediacentre/factsheets/fs310/en/index1.html

Wu, Y., Zhang, D., \& Kang, S. (2013). Physical activity and risk of breast cancer: a meta-analysis of prospective studies. Breast cancer research and treatment, 137(3), 869-882. https://doi.org/10.1007/s10549-012-2396-7 
Yang, W.-S., Deng, Q., Fan, W.-Y., Wang, W.-Y., \& Wang, X. (2014). Light exposure at night, sleep duration, melatonin, and breast cancer: a dose-response analysis of observational studies. European Journal of Cancer Prevention, 23(4), 269-276. https://doi.org/10.1097/CEJ.0000000000000030

Youlden, D. R., Cramb, S. M., Dunn, N. A., Muller, J. M., Pyke, C. M., \& Baade, P. D. (2012). The descriptive epidemiology of female breast cancer: an international comparison of screening, incidence, survival and mortality. Cancer epidemiology, 36(3), 237-248. https://doi.org/10.1016/j.canep.2012.02.007

\section{Copyrights}

Copyright for this article is retained by the author(s), with first publication rights granted to the journal.

This is an open-access article distributed under the terms and conditions of the Creative Commons Attribution license (http://creativecommons.org/licenses/by/4.0/). 